Fecha de recepción: noviembre 2018 Fecha de aceptación: marzo 2019 Versión final: julio 2019

\section{História, Memória e Nação: as narrativas construídas por Ricardo \\ Levene em seu Ensayo histórico sobre la Revolución de Mayo y Mariano Moreno (1920) sobre o liberalismo de Maio de 1810}

Mariana Schossler *

Resumo: Este trabalho tem por objetivo analisar a obra Ensayo histórico sobre la Revolución de Mayo y Mariano Moreno (1920), escrita por Ricardo Levene (1885-1959), professor e membro da Junta de Historia y Numismática, e inserida no contexto das comemorações do centenário da Revolução de Maio de 1810, onde utilizou-se da trajetória de um dos principais líderes de Maio para dissertar sobre a importância do liberalismo para a Revolução. Pretende-se, aqui, analisar as narrativas que Levene construiu sobre a Revolução de Maio e Mariano Moreno, procurando compreender a memória que construiu acerca do fato histórico e do personagem como, também, a importância de tais construções para o momento vivido pela nação.

Palavras chave: Ricardo Levene - Mariano Moreno - Historiografia argentina - Memória - Comemoração.

[Resumos em espanhol e inglês na página 247]

${ }^{(*)}$ Graduada em História pela Universidade do Vale do Rio dos Sinos - UNISINOS (2013), Mestre em História pela mesma Universidade (2016) e Doutoranda em História, também pela mesma Universidade. E-mail: marianaschossler@yahoo.com.br

Em 1920, o historiador argentino Ricardo Levene (1885-1959), professor universitário e membro da Junta de Historia y Numismática, publicou uma de suas maiores obras, composta de dois volumes, com cerca de seiscentas páginas cada, e intitulado Ensayo histórico sobre la Revolución de Mayo y Mariano Moreno. Neste trabalho, reflete sobre o movimento de Maio de 1810 a partir da trajetória de um de seus principais líderes, o advogado Mariano Moreno. Levene defende a tese de que as ideias do personagem a quem biografa foram inspiradas pela Ilustração francesa e, por isso, procura ressaltar a importância do liberalismo para a Revolução, evidenciando sua presença nos escritos de Moreno e em seu projeto político para Buenos Aires. 
Contudo, a defesa das ideias do líder revolucionário se dá em um momento no qual a Argentina havia acabado de comemorar o centenário de Maio e Levene se encontrava em evidente ascensão enquanto historiador, participando, inclusive, da campanha de profissionalização de seu ofício. Neste sentido, o principal objetivo deste trabalho é analisar as narrativas que Levene construiu sobre a Revolução de Maio e Mariano Moreno, procurando compreender a memória que construiu acerca do fato histórico e do personagem como, também, a importância de tais construções para o momento vivido pela nação.

Levene (1885-1959) defendeu sua tese ${ }^{1}$ junto à Facultad de Derecho y Ciencias Sociales da Universidad de Buenos Aires (UBA), em 1905. Durante seus estudos, travou contato com professores e intelectuais com os quais conviveu, inclusive alguns de seus colegas ${ }^{2}$, conhecidos como membros da Nueva Escuela Histórica ${ }^{3}$. A partir de 1905, sua atividade profissional girou em torno da investigação histórica e da docência, iniciada em 1911, nas disciplinas de História, Sociologia e Direito nos níveis primário, secundário e universitário. Como professor, atuou junto à Universidad de Buenos Aires e em La Plata. A atuação de Levene se solidificou quando do seu ingresso junto a instituições de cunho historiográfico e através do exercício de cargos importantes junto a elas. O historiador ingressou em 1914, com 29 anos, na Junta de Historia y Numismática, na qual exerceu cargos de secretário, vice-presidente e presidente ${ }^{4}$.

Enquanto historiador, Levene procurou seguir uma linha de trabalho bastante específica. Segundo Escudero (2010), ele procurou construir uma tradição historiográfica que se queria herdeira de Bartolomé Mitre e que deveria ter continuidade por intermédio de seus discípulos. Como principais influências de seu trabalho, podem-se identificar autores como Rafael Altamira (com quem, segundo Beired (2009), ele estabeleceu frutivo contato, Comte e Ernest Lavisse ${ }^{5}$. Para além destes referenciais, deve-se considerar, também, a obra de Charles Langlois e Charles Seignobos, Introducción a los estudios históricos, amplamente utilizada, à época, por muitos historiadores como manual de metodologia. Durante a década de 1930, com a Restauração Conservadora, o historiador esteve muito próximo do governo, ao atuar como assessor em questões culturais e educacionais e, também, como conselheiro do presidente Agustín P. Justo. É importante considerar, também, que Levene procurou desenvolver a cultura histórica e patriótica argentina com a colaboração do Estado, realizando um trabalho bastante próximo àquele feito por Ernest Lavisse na França, que se propôs a construir uma história nacional unificadora, sem demonstrar as fissuras da nação argentina ${ }^{6}$.

A ascensão profissional de Levene deu-se em um período bastante especifico da história argentina. A publicação do Ensayo $(1920)^{7}$ se insere em um período no qual Levene desfrutava de prestígio e reconhecimento profissional e no qual a Argentina vinha enfrentando uma série de questões enquanto nação, tais como aquelas decorrentes da imigração massiva, que trouxe milhares de pessoas para o país, em uma política de branqueamento da população; das comemorações do centenário da Revolução de Maio, em 1910 e das tentativas de construção de uma memória sobre o movimento; das disputas pela presidência nesta década e dos projetos de governo esboçados pelos diferentes grupos; e, ainda, aqueles resultantes da própria profissionalização do ofício de historiador. Todos estes aspectos influenciaram a maneira como Levene pensou o personagem Mariano Moreno e a forma como construiu sua narrativa sobre o mesmo. 
Segundo Lopes (2012), cerca de 4.200.000 imigrantes ingressaram na Argentina entre os anos de 1881 e $1914^{8}$. A maioria dos imigrantes era composta de homens jovens e de origem rural, que procuravam terras no interior do país para ocupação e cultivo. Estimativas apontam que cerca de $30 \%$ da população do país, à época, era formada de estrangeiros ${ }^{9}$. E a chegada deste grande contingente populacional coincidiu com uma notável expansão econômica. Para Felix Luna (2010), a década de 1880 e as subsequentes podem ser denominadas de "años de prosperidad", por conta o grande crescimento econômico alcançado pelo país. Tais características seriam devidas, principalmente, ao governo do general Julio Argentino Roca. Segundo Luna (2010, p. 10-11),

[...] una circunstancia insólita marca su desempeño como presidente: la de haber sido el único, desde 1853, que ocupó por dos períodos completos a que se lo destacara en la historia política argentina, pero no es el único hecho que distingue su trayectoria. La fundación de La Plata, la conquista del Chaco, la organización política y poblacional de la Patagonia, el impulso de tendencias económicas que marcaron durante años la inserción del país en los circuitos mundiales de la producción y el consumo son importantes acontecimientos que se asocian a la gestión e Roca. También lo serán la inmigración masiva, las soluciones a los conflictos limítrofes con los países vecinos y las polémicas religiosas y educativas de la época.

Desde a presidência de Roca até a Primeira Guerra, a Argentina viu uma sucessão de governos liberais que procuravam seguir um modelo de crescimento baseado na produção industrial e na agregação das massas de trabalhadores à economia. Por conta, principalmente, de suas lavouras, o país vinha se destacando no mercado internacional, e as elites aspiravam viver de modo como se estivessem em uma metrópole europeia (Luna, 2010). Por outro lado, na década de 1900 houve tentativas de revolução radical e os grupos anarquistas e comunistas cresceram em tamanho e influência. O processo eleitoral de 1910, ocorrido meses antes das comemorações, resultou na eleição de Roque Sáenz Peña, e mudanças na lei eleitoral em seu governo propiciaram, ainda na mesma década, a chegada de radicais e socialistas ao poder.

O centenário de Maio foi festejado a partir de atos organizados não apenas pelo governo, mas, também, por particulares. A própria cidade de Buenos Aires contou com uma Comisión Municipal del Centenario, e foram organizados atos públicos, que contaram com a presença de delegações estrangeiras ${ }^{10}$ e intelectuais europeus ${ }^{11}$. Por outro lado, as comemorações foram marcadas por intensos protestos de organizações de trabalhadores, que reivindicavam alguns direitos em relação à residência e seus dirigentes ${ }^{12}$.

Outras iniciativas dizem respeito às tentativas de construção de uma memória sobre a Revolução de Maio em seu centenário. Houve, por exemplo, a publicação de uma grande quantidade de obras e textos. Em sua maioria, estes tinham o objetivo de rememorar Maio de 1810 e construir o que Maurice Halbwachs (1990) denominaria "memória coletiva"13. Todas estas iniciativas visavam à integração dos imigrantes com a história da pátria que adotaram e a construção de uma memória sobre o passado argentino para a população em geral do país, visando a inseri-la em um lugar que lhe estaria destinado (Fradkín \& Gelman, 2010). 
Os anos subsequentes às comemorações do centenário de Maio viram a chegada de um governo radical ao poder, com a eleição, em 1916, de Hipólito Yrigoyen, rompendo com a hegemonia liberal das décadas pregressas. É neste contexto que se desenvolve a Reforma Universitária de 1918 e ganha fôlego a profissionalização do ofício de historiador, através da docência nos círculos universitários, o ingresso de historiadores em instituições que visavam ao controle das práticas historiográficas, como a Junta de Historia e Numismática e um intenso esforço de produção de obras e textos, organização de arquivos e edição e publicação de fontes.

A Reforma Universitária eclodiu em Córdoba no ano de 1918 e prontamente espalhou-se para o resto do país. A emergente classe média letrada aspirava pelo acesso à Universidade, já que toda uma geração de intelectuais argentinos via nas universidades uma possibilidade de ascensão acadêmica e social, o que fez com que apoiassem o movimento (Bernheim, 1998). Note-se que Ricardo Levene foi um dos indivíduos que também se apropriou da Reforma Universitária, mesmo que não atuasse em Córdoba. O historiador já vinha trabalhando como docente há alguns anos. Entretanto, era ainda bastante jovem em 1918, o que pode explicar o seu interesse neste movimento. Do ponto de vista da conformação da História enquanto disciplina, um dos pontos mais importantes defendidos por intelectuais como Levene era o fato de que apenas lecionassem nos cursos superiores professores especialistas em sua área de conhecimento. Ou seja, apenas historiadores poderiam atuar como docentes nos cursos de História, o que abriria um vasto campo de trabalho para estes profissionais com formação recente na disciplina.

No ano de 1920, ainda no governo de Yrigoyen, e em um momento no qual Ricardo Levene se utiliza dos esforços pela profissionalização do ofício de historiador para alcançar prestígio profissional, vem à luz o Ensayo (1920). Esta foi sua primeira grande obra destinada ao personagem, que foi revisitado em 1938 e em $1948^{14}$, ano em que encerra suas atividades como professor na Universidad de Buenos Aires e na Universidad de La Plata, em função de sua aposentadoria. Neste meio tempo, Levene desenvolveu, ainda, outros projetos, alguns deles em parceria com o Estado argentino, como a coleção Historia de la nación argentina (1936). É importante observar, contudo, que o contexto no qual a publicação do Ensayo (1920) se insere diz respeito à própria atuação de Levene enquanto intelectual, já que esta obra, principalmente quando analisada tendo em vista as questões já colocadas, marca uma posição sobre a Revolução de $\mathrm{Maio}^{15}$ enquanto fato histórico e sobre Mariano Moreno enquanto seu líder.

Mariano Moreno era formado em Direito pela Universidade de Charcas, e teve seu pensamento bastante influenciado por ideias ilustradas. Moreno possuía um posicionamento político muito bem definido, influenciado, em alguns aspectos, pelo Iluminismo europeu do século XVIII, e tendo como modelo a Revolução Francesa. Seu contato com soldados ingleses durante as invasões destes ao Rio da Prata entre os anos de 1806 e 1807 fizeram, também, com que tivesse contato com a ideia do livre-comércio. A partir disso, Moreno torna-se um dos representantes do pensamento liberal de inícios do século XIX, sendo considerado, até os dias de hoje, um dos principais pensadores da questão independentista no Rio da Prata do início do século XIX (Shumway, 2009; Gaut Vel Hartman, 2010).

Em 1805, assumiu cargos na Audiência e no Cabildo de Buenos Aires. Dada sua formação acadêmica, atuou também como advogado e no auxílio a indivíduos que o procuravam 
para a redação de documentos, utilizados para os mais diversos fins. Moreno deixou diversos escritos, dentre eles, a Representación de los Hacendados (1809), no qual condensa parte dos ideais políticos dos diversos grupos que lutavam pelo poder no período. Eleito secretário da Primeira Junta, teria manifestado sua concepção de governo para a nova nação em seu documento intitulado Plan de Operaciones (1810). Segundo Gaut vel Hartman (2010), Moreno procurava estabelecer as bases para uma revolução profunda das estruturas políticas do Vice-reino do Rio da Prata, o que levaria em consideração não apenas a remoção das autoridades coloniais dos postos mais altos do governo, mas, também, a obtenção da independência e a escrita de uma Constituição. Faleceu em 1811, durante uma viagem à Grã-Bretanha, onde deveria atuar como embaixador. Embora tenha tido uma curta atuação após a Revolução de Maio, por conta de seu falecimento prematuro, os escritos de Moreno (ou a ele atribuídos) chamam a atenção pela complexidade das informações neles inseridas.

Pensar esta elaboração de um personagem e de um acontecimento por uma sociedade requer que consideremos que a memória, para além da questão cognitiva, psíquica, subjetiva e completamente individual, contenha em si aspectos que a dimensionem como um fenômeno também coletivo e social, construído coletivamente e submetido a flutuações, transformações e mudanças constantes, que advém do contexto histórico no qual tal memória é acessada e reconstruída. Tal é a perspectiva de Pollak (1992), para quem a memória, no seu sentido coletivo, pode incorporar eventos que não se situam nem no espaço e nem na temporalidade vivida pelos indivíduos, já que “é perfeitamente possível que, por meio da socialização política, ou da socialização histórica ocorra um fenômeno de projeção ou de identificação com determinado passado, tão forte que podemos falar numa memória quase que herdada" (Pollak, 1992, p. 2). E é exatamente pelo fato de que esta memória socializada seja organizada por datas, monumentos e tradições que ela se torna extremamente seletiva, refletindo o momento em que é acessada e utilizada. Neste processo, que o autor denomina trabalho de enquadramento da memória, uma das principais responsáveis é a historiografia que, a partir do século XIX, para a Europa, e do século $\mathrm{XX}$, para o caso argentino, se preocupa com a formação de uma história nacional, principalmente em países onde a unificação se deu tardiamente.

Com a narrativa historiográfica ocorre um processo análogo, já que, dependendo das intenções (conscientes ou não) do historiador, algumas características do personagem podem ser exaltadas em detrimento de outras, e o contínuo processo de reconstrução da memória pode fazer com que outros historiadores, com outras intenções, ressaltem, por sua vez, facetas não consideradas do mesmo indivíduo. Ao mesmo tempo, e quando a intenção é o elogio, tem-se uma espécie de modelo de construção textual, colocada nos seguintes termos por Joël Candau (2012, p. 143):

A prosopopeia memorial apresenta várias características de Exemplum: idealização, personagens-modelos nos quais são mascarados os defeitos e enaltecidas as qualidades, seleção de traços de caráter julgados dignos de imitação, 'lendas de vidas' post mortem que podem fabricar [...], transcendendo as qualidades pessoais do defunto 'através de um modelo que combina arquétipos e estereótipos’ etc. A emulação dos grandes homens do passado pode então 
manifestar-se a partir de formas de tanatocracia ou, mais comumente, por tentativas de panteonização, que serão sempre jogos identitários para o grupo, sociedade ou nação.

É a partir da ideia do exemplum que gostaria de introduzir, neste texto, a análise do Ensayo (1920). Embora a obra refira-se, também, à Revolução de Maio -principalmente a seus aspectos sociais e econômicos-, a trajetória de Moreno encontra-se diluída no texto. É notório que tal estratégia narrativa possuía um objetivo muito bem definido, exposto já no prefácio intitulado Una palabra:

Obrero de un programa colectivo de construcción del pasado argentino, este libro es fruto de pacientes investigaciones realizadas en nuestros archivos. No es sino un ensayo, como dice lealmente su título. Las fundadas observaciones que se formulen y nuevas pruebas documentales que se publiquen, podrán rectificar o integrar la visión de la escena y de los hombres de un momento de nuestra historia, que el autor ha contemplado. (Levene, 1920, Tomo I, p. VII, grifos meus).

No trecho acima, Levene assume a intenção de construção de um passado para a Argentina, em um momento importante para a compreensão das possíveis intenções do historiador ao evocar a trajetória de Moreno em 1920. Acredito que a maior intenção do autor seja apontar Moreno como um dos representantes do pensamento liberal latino-americano de inícios do século XIX. Esta inflexão fica mais clara ao analisar-se o texto como um todo.

A obra é dividida em diversos capítulos, cuja organização se dá em ordem cronológica, iniciando já nas últimas décadas do século XVIII -com a criação do Vice-reino do Rio da Prata e as reformas bourbônicas, bem como o nascimento de Moreno-, embora tenha por foco os acontecimentos ocorridos entre os anos de 1806 e 1810. Ainda no primeiro capítulo, Levene discorre, em certa medida, sobre o que considerava o processo de emergência de uma noção de nacionalidade nos domínios coloniais espanhóis ainda antes da Independência. Para tanto, constrói seu raciocínio alegando que aconteceram outras revoltas entre os séculos XVI e XVIII. Entretanto, "faltaba al organismo que tales conmociones sufría la puberdad física y el desarrollo económico, que las revisten de su verdadero valor como exponentes de necesidades colectivas" (Levene, 1920, Tomo I, p. 2).

Para o autor, é a consciência das necessidades coletivas, de uma determinada população, bem como uma unidade territorial ou cultural que iniciam o processo de formação das nacionalidades, tão importante para o posterior processo de independência. Para tal constatação, Levene baseia-se, principalmente, no caso europeu, cujos diferentes Estados foram construindo suas nacionalidades com o passar de vários séculos:

La nacionalidad es siempre una unidad espiritual sin duda, pero se eleva sobre la base de unidades físicas fundamentales. A veces, es el territorio que, a manera de continente, imprime formas determinadas al contenido; no obstante la variedad geográfica, otras veces operan los intereses comunes, que derivan del medio $y$ fuentes de producción, y del vínculo de las partes reunidas en los puntos de circulación o exportación de la riqueza. Cuando estas unidades físicas (geográfica, 
económica o étnica) se han consolidado, otras de carácter psicológico y moral integran la obra de la nacionalidad. En términos generales, éste ha sido el proceso de la formación de los estados europeos del occidente durante los siglos XIII al $\mathrm{XV}$; de la Europa del centro, que se prolonga hasta los sucesos del 70, y de las nacionalidades de la Europa oriental (Levene, 1920, Tomo I, p. 3, grifos meus).

Neste sentido, o autor transplanta um "modelo" de nacionalidade -que é discutível, dadas as particularidades das diferentes regiões da Europa- para a América platina de finais do século XVIII. E vai mais longe: aponta que tal processo se deu a partir da definição das "unidades físicas", fusão das raças, desenvolvimento econômico e primeiras manifestações de consciência social.

Tal ha sido el proceso de nuestra nacionalidad. Con la época del virreinato se inicia un ciclo de intensa evolución histórica, definiéndose las 'unidades físicas', la fusión de razas operada en el período precedente y el desenvolvimiento de orden económico; y aparecen en todos los puntos del territorio las primeras manifestaciones de la conciencia social.

En un medio geográfico y económico de destacada variedad, la sociedad del Plata ha evolucionado con lentitud hasta mediados del siglo XVIII. Débiles eran las reacciones acusadas por el inmenso organismo cuyas distintas partes se diferenciaban entre sí por virtud de los peculiares caracteres de cada región (Levene, 1920, Tomo I, p. 3).

A nacionalidade surgiria, assim, a partir da consciência social surgida por conta das necessidades das populações. As diferentes regiões, com suas especificidades, teriam constituído nacionalidades distintas já durante o período colonial. Fato é que tais afirmações podem ser bastante relativizadas ao analisarem-se as acepções do vocábulo nação no século XVIII. Para Nora Souto e Fabio Wasserman (2008, p. 83, grifos meus), havia, à época, diversos significados para o conceito: "por un lado hacía referencia al lugar de nacimiento, empleo ya registrado en el ámbito de las universidades y los concilios eclesiásticos medievales", era utilizado para "distinguir a una población caracterizada por una serie de rasgos étnicos o culturales como lengua, religión o costumbres" e, também, para "designar a poblaciones que compartían unas mismas leyes o debían obediencia a un mismo poder, acepción política que había comenzado a difundir desde principios del setecientos".

É importante notar que, nestas três acepções, há diferenciações entre uma identidade étnica que atribua traços de nacionalidade a uma determinada população e a questão política de uma delimitação territorial e administrativa arbitrária, que pode agregar, sob o mesmo governo, populações muito diferentes do ponto de vista de seu caráter identitário e, portanto, nacional. Neste sentido, pode-se questionar a ideia de formação de uma nação ainda durante o período colonial, pela própria imprecisão do termo. Afinal, quais seriam os traços tão marcantes das características apontadas por Levene (definição das "unidades físicas", fusão das raças, desenvolvimento econômico e primeiras manifestações de consciência social) que caracterizariam como nação os territórios do Rio da Prata e que os diferenciariam de outros vice-reinos espanhóis? É a partir destes questionamentos que 
Souto e Wasserman (2008) apontam a ideia de construção, lenta e contínua, da ideia de nação na região platina, impulsionada, principalmente, pelos diferentes Estados formados a partir do processo independentista.

Os argumentos utilizados pelo autor para defender sua tese sobre o surgimento do sentimento de nacionalidade na região do Rio da Prata aponta para uma tentativa de demonstrar ao seu leitor que a população da região passou, aos poucos, a tomar consciência da possibilidade de um governo autônomo. Entretanto, como afirma Chiaramonte (1993, p. 50), "El afán por afirmar los débiles estados surgidos del derrumbe ibérico, fomentando la conciencia de una nacionalidad distinta, propósito explícito en esa historiografía, facilitó la generalizada suposición de que la Independencia fué fruto de la necesidad de autonomía de nacionalidades ya formadas". É a partir deste pressuposto de uma identidade nacional que anseia por autonomia que Levene acaba por construir sua argumentação sobre Moreno, ao apontar que o líder revolucionário possuía um projeto político liberal para a nova nação que emergiria, fomentado pela circulação de ideias entre os dois lados do Atlântico nas décadas anteriores.

Levene, ainda no início do primeiro tomo, aponta que no final do século XVIII e inícios do XIX, diversos fatores contribuíram para a preparação do clima intelectual que fomentou o movimento independentista, entre eles "la filtración cada vez más penetrante de la filosofía y economía liberal", bem como "la irradiación contagiosa de la independencia de las colonias de la América del Norte" e "las nuevas ideas que la Revolución francesa había esparcido por el mundo fueron asimiladas con rapidez y se incorporaron a la vida orgánica de la naciente sociedad". Por fim, cita "la activa y nueva política inglesa en la América española, la creciente entrada de extranjeros, fomentada especialmente por la legislación sobre comercio libre de negros, aceleraron el desenvolvimiento social que se venía cumpliendo en el imperio indiano" (Levene, 1920, Tomo I, p. 18-19).

Nas páginas seguintes de seu estudo, Levene vai agregando informações sobre a formação de Moreno, bem como das ideias por ele proferidas em seus primeiros escritos. Ao falar sobre as leituras feitas pelo líder revolucionário enquanto cursava a Universidade de Chuquisaca, comenta: "En uno de los más conspicuos representantes de la generación revolucionária del Plata, Mariano Moreno, acaso han tenido tanta significación política las lecturas y comentarios del Contrato social de Rousseau, como de la Política indiana de Solórzano" (Levene, 1920, Tomo I, p. 39). Mais adiante, analisa a Disertación jurídica sobre el servicio personal de los indios en general y sobre el particular de Yanaconas y Mitarios (1802), escrita por Moreno para um de seus exames do curso. O historiador aponta que o texto inicia com uma defesa da liberdade dos indígenas, que se torna, aos poucos, um estudo sobre a condição do índio na América, focando os casos das populações de Yanaconas e Mitas. Levene termina a análise do texto com a seguinte afirmação: "De más carácter jurídico que histórico y de más valor político que jurídico, la Disertación doctoral de Mariano Moreno es como su profesión de fe. Vibran en estas páginas de adolescente las pasiones dominantes de su vida: la justicia y la libertad. Así iniciaba su vida pública confesando sus ideas liberales y su amor por los humildes" (Levene, 1920, Tomo I, p. 86).

As diversas referências às ideias das revoluções na França e na América do Norte, bem como as citações do conceito de liberalismo e das ideias de liberdade e justiça contribuem para formar a imagem de um Moreno que o autor quer ilustrado, preocupado com 
questões sociais e, ainda, liberal. Talvez a chave para o sucesso desta representação seja a repetição destas características intelectuais do revolucionário ao longo do texto, reforçando, ao longo de quase setenta páginas, a importância destes conceitos na trajetória do personagem. Este afinco de Levene em corroborar sua tese aponta para uma necessidade do momento histórico vivido pela Argentina, já mencionado anteriormente, no qual nasceu, cresceu e tornou-se historiador, onde poderia ser útil, para legitimar o presente, apontar o sucesso dos ideais da Ilustração e do liberalismo já desde a época revolucionária.

Na sequência, Levene passa a dissertar sobre as causas do movimento e, também, sobre a própria Revolução de Maio, utilizando-se de longas páginas para comentar, de forma bastante detalhada, todos os passos seguidos pelos revolucionários. Note-se, entretanto, que, já no segundo tomo da obra, o historiador atribui a Moreno o papel de espectador em alguns dos acontecimentos, embora atribua a este personagem outro papel no processo que, para o autor, parece ainda mais importante:

Fué un espectador simplemente, pero sus miras de hombre superior debieron desplegarse desde el 22 de mayo, para abarcar la vastedad del cuadro. Y cuando por el imperio de las circunstancias pasó a ocupar un cargo de responsabilidad, llenó el vacío señalado, mezclándose con la multitud, pero no en el medio, sino a su frente; fué el director espiritual de la revolución (Levene, 1920, Tomo II, p. 70-71, grifos meus).

Tomando Moreno como diretor espiritual, Levene leva seu leitor a considerar o revolucionário como o pensador da Revolução, aquele a quem se atribuíram as diretrizes intelectuais dos feitos dos homens tidos como próceres de Maio. Tal inflexão é importante, já que, dada a prematura morte de Moreno, este não pôde participar, como militar, da guerra de independência iniciada, atuação esta que logrou honras para indivíduos como Manuel Belgrano e José de San Martín. Atribuir um papel tão relevante ao personagem estudado, em detrimento de outras possibilidades, faz com que Levene possa inscrever seu personagem no panteão dos revolucionários que merecem ser lembrados pela nação argentina a partir de um outro registro, o de um homem dedicado a trabalhar pela causa revolucionária a partir de suas ideias.

Exemplo desta inflexão se deu também, quando da instituição de um monumento dedicado ao próprio Moreno em 1910 pela Comisión Municipal del Centenario de Buenos Aires, que, para a comemoração dos cem anos da Revolução, o solicitou ao artista Miguel Blay y Fábregas e que foi assentado nos limites da Plaza del Congreso. Segundo Aguerre (2005, p. 55, grifos meus), o monumento possui as seguintes características:

La misma representa a la figura del prócer situada en la cima de un alto basamento en piedra irregular, concebido a la manera de una montaña. Mariano Moreno, sedente y representado con la vestimenta de la época, presenta una actitud de fuerza y pujanza al mirar hacia el horizonte con su rostro altivo. Apoya su puño izquierdo cerrado, casi contenido, en la rodilla izquierda. Su mano derecha, en cambio, toma una pluma, reflejando así su oficio de escritor. En cuanto a la utilización de recursos simbólicos merece destacarse la presencia 
del cóndor, que vuela por detrás y a los pies de la figura de Moreno, demostrando así el artista que el pensamiento del homenajeado resultaba difícil de superar, aun por el rey de los Andes.

Tal processo de eleição de um personagem por uma comissão a ser rememorado, a elaboração de um projeto ou esboço de um monumento, a contratação de um artista, a escolha de um espaço onde assentá-lo, faz parte de uma pedagogia da memória nacional, onde cada elemento representa um aspecto da trajetória ou atuação do indivíduo. Como assinalado na citação acima, a pluma na mão de Moreno reflete seu ofício de escritor, e a presença do condor simboliza o fato de que o pensamento do revolucionário era difícil de ser superado. Tais aspectos refletem o reconhecimento de que a atuação do personagem não se deu no âmbito militar da guerra de independência, como no caso de outros líderes do acontecimento, mas sim do ponto de vista intelectual, e reforçam a ideia de que Moreno deve ser lembrado por estas características.

O fato de que a biografia de Moreno está diluída ao longo do texto do Ensayo (1920) abre espaço privilegiado de análise dos documentos escritos pelo próprio biografado, um dos poucos revolucionários do período que contou com uma efetiva produção de textos que traziam no seu conteúdo um projeto de construção para o Estado argentino. Seus escritos são associados à Ilustração, principalmente por conta das ideias neles contidas e das associações, já vistas anteriormente, às leituras de autores como Rousseau. Por outro lado, e justamente por tais associações, Levene procura nos escritos e no pensamento de Moreno o pensamento liberal que, segundo o autor, teria guiado a Revolução de Maio. Talvez o principal problema da obra de Levene resida no fato de que o autor dá grande importância à figura e ao pensamento de Moreno como construtor de um projeto de revolução, que acaba por ignorar as demais forças políticas atuantes no momento, muitas das quais ou não queriam uma efetiva independência, ou procuravam garantir a manutenção do status quo. Esta crítica leva ainda a outra percepção sobre o uso que Levene faz dos documentos por ele utilizados para a reconstituição da Revolução. Como secretário da primeira Junta de Governo, Moreno produziu grande quantidade de documentos que, por conta do cargo que ocupava, levavam sua assinatura. Penso que a indicação de Moreno para este cargo tenha se dado justamente por conta da experiência que este adquiriu durante sua atuação como advogado, quando, como assinalado anteriormente, auxiliava alguns civis na escrita de documentos necessários para questões particulares. Ao mesmo tempo, por ser advogado, evidentemente dominava questões legais.

Neste sentido, é exatamente o fato de os documentos da Junta serem assinados por Moreno o que pode ter provocado uma confusão (intencional ou não) por parte de Levene, pelo fato de que, ao encontrar a assinatura de Moreno nos documentos, o historiador atribua a autoria do mesmo ao revolucionário, embora o conteúdo possa ser (e provavelmente é) de construção coletiva, com a participação dos demais membros da Junta. É importante notar que, à época, a noção de autoria não era a mesma que temos atualmente e poderia haver uma grande diferença entre ser autor ou redator de um texto. Para Roger Chartier (2010, p. 16): 
[...] supõe-se uma relação originária e indestrutível entre a obra e seu autor. Ora, uma ligação como essa não é universal nem imediata, pois, se todos os textos foram realmente escritos ou pronunciados por alguém, nem por isso todos são atribuídos ao nome de uma pessoa. [...] nos obriga a abandonar a tentação de, implícita e indevidamente, considerar como universais categorias cuja formação ou uso são historicamente bastante variáveis.

A relação entre autoria de um discurso e a colocação deste em formato escrito, seja manuscrito ou impresso, é mais complexa do que parece. $\mathrm{O}$ fato de que o texto conte com a assinatura apenas de Mariano Moreno não garante que este tenha sido o único autor do texto, que pode ter sido elaborado em grupo e que pode ter sofrido uma série de adições e modificações à medida que foi sendo copiado.

Assim, ao eleger o revolucionário como o mote para suas investigações sobre a Revolução de Maio, Levene acaba alçando-o ao papel de principal pensador do movimento, principalmente por conta da grande quantidade de documentos que assinou. Isto se dá, ainda, em um momento onde a Argentina, enquanto nação, viu-se, após um período de predomínio de políticas liberais, inserida em um contexto de imigração massiva, emergência de grupos radicais, que chegaram ao poder, Reforma Universitária e outros conflitos. Levene, no crescimento de seu prestígio profissional, recupera Moreno e o alça ao papel de um homem que possuía um projeto político para a nação em formação, que era liberal e que se afastava da tradição espanhola de governo. A necessidade advinda da identidade nacional em gestação teria feito com que Moreno, como escritor, se utilizasse das ideias, e não da força, para atuar em prol da causa americana.

\section{Notas}

1. Segundo Eduardo Escudero (2010, p. 51), "En la Facultad de Derecho y Ciencias Sociales obtuvo su doctorado mediante una tesis que estudiaba las 'Leyes Sociológicas', en donde '(...) postula la necesidad de estudiar los hechos sociales en su complejidad a partir de un abordaje ecléctico, tomando elementos de las diferentes corrientes sociológicas (...)'. Su actividad profesional tuvo facetas bien definidas y ampliamente desarrolladas: la docencia en Historia, Sociología y Derecho y la investigación histórica”. É necessário mencionar, contudo, que o autor não cita o título da tese defendida por Levene, considerando apenas a temática.

2. Foram seus colegas na Facultad de Derecho y Ciencias Sociales homens como Emilio Ravignani, Diego Luis Molinari, Luis Maria Torres e Rómulo Carbia (Devoto \& Pagano, 2009). 3. A Nueva Escuela Histórica se destacava, em primeiro lugar, por sua vinculação tanto com universidades, onde seus membros atuavam como professores, quanto com instituições leigas que valorizavam o conhecimento histórico, como o Instituto Ravigani e a Academia Nacional de la Historia. E, em segundo lugar, pela campanha de profissionalização da disciplina histórica, o que explica as reivindicações para que somente historiadores, com a devida formação acadêmica, ocupassem postos de ensino e de pesquisa. Além disso, tinha como principal característica o rigor metodológico e a crítica às fontes. Observa-se, ainda, 
que os historiadores da Nueva Escuela buscavam realizar as discussões acerca dos conteúdos e resultados de suas obras, corroborando ou rechaçando hipóteses, não apenas no ambiente institucional ao qual estavam vinculados, mas, também, e principalmente, através das "redes de crítica". Entre os principais nomes filiados mesma, destacam-se Emilio Ravignani, Ricardo Levene, Diego Luis Molinari, Rómulo Carbia e José Torre Revello, entre outros.

4. Foi sob seu comando que, em 1938, a instituição foi reconhecida oficialmente e denominada Academia Nacional de la Historia Argentina (ANH).

5. Lavisse (1842-1922) foi um dos principais nomes da escola metódica francesa. Dedicou-se, a partir do ano 1900, à publicação da monumental coleção intitulada Histoire de France, que serviu de modelo a diversos historiadores, inclusive o próprio Levene. Lavisse também escreveu manuais escolares de História.

6. Eduardo Escudero (2010, p. 56-57, grifos meus) aponta que "Con tal cúmulo de actuaciones profesionales e institucionales, al llegar el decisivo año 1945, y transcurrida la década del treinta, Ricardo Levene no sólo estaba en la cumbre de su carrera profesional y desempeñaba múltiples cargos en diferentes instituciones, sino que ocupaba, sin duda, un lugar relevante en el mundo cultural e historiográfico argentino. A pesar de la crisis institucional provocada por el Golpe de Estado de 1930 y las incertidumbres políticas e ideológicas del período 1930-1945, el ascenso institucional de Levene no conoció. Muy por el contrario, su carrera se afianzó y el historiador intervino desde y en el Estado en tanto mentor decisivo. 7. Utilizar-me-ei, a partir deste momento, da abreviatura Ensayo (1920) para me referir à obra de Levene aqui analisada. Tal estratégia visa uma maior fluidez do texto e a tentativa de evitar repetições desnecessárias do título completo do trabalho.

8. Estas pessoas chegaram ao país a partir de duas grandes ondas, que tinham características diferentes: "[...] a imigração de massas na Argentina ocorreu em duas grandes ondas até a Primeira Guerra Mundial: a primeira foi na década de 1880, período em que imigou o maior número de famílias e a porcentagem de retorno foi menor em todo o período estudado. O grande número deles era de colonos decididos a aproveitar as possibilidades que eram oferecidas pelas terras disponíveis, dada a expansão da fronteira e os altos preços de grãos para os custos de produção argentina. Já a segunda grande onda migratória se deu nos primeiros anos do novo século, cujos traços não foram diferentes dos do período anterior" (Lopes, 2012, p. 22-23).

9. Uma das principais questões a ser considerada no tocante à imigração diz respeito à integração destas pessoas à sociedade argentina. Se sua chegada coincidiu com um grande crescimento econômico, muito bem-vindo neste contexto, por outro lado, estes grupos não possuíam uma conexão identitária com o passado argentino. Antes do influxo imigratório, grande parte da população argentina era composta por grupos indígenas e seus descendentes. Além disso, havia uma grande miscigenação entre brancos, negros e indígenas. Os imigrantes, em sua maioria eurpeus, participaram de uma política de branqueamento na Argentina. Para além da questão da inserção destas pessoas na sociedade argentina, era necessário, para uma efetiva política de integração, que esta população conhecesse a história do país no qual passava a residir e, também, se identificasse com esse passado. Tais questões se tornaram ainda mais prementes quando das comemorações do centenário da Revolução de Maio, em 1910, momento em que a construção de uma memória sobre o fato histórico em si e sobre a construção de uma nação se tornou importante. 
10. No porto de Buenos Aires desembarcaram delegações vindas de Nova York, Amsterdã, Marselha, Gênova, Liverpool, Japão, etc. Os embaixadores considerados mais ilustres foram hospedados em palácios bonaerenses: Isabel de Bourbon ficou hospedada no palácio de Bary, na avenida Alvear, por exemplo. O presidente do Chile foi recebido em um palco no Paseo de Julio. Já o vice-presidente do Peru assistiu ao desfile militar do dia 25 de maio na Plaza de Mayo. As delegações foram, também, convidadas a assitir a uma apresentação do barítono italiano Titta Ruffo no Teatro Colón.

11. Foram convidados para a ocasião os espanhóis Jacinto Bonavente, Vicente Blasco Ibáñez e Ramón del Valle Inclán e os franceses Georges Clemenceau, Anatole France e Jean Jaurès. Segundo Luna (2010, p. 183), algumas destas visitas resultaram em relatos posteriormente publicados:"Algunos escribieron luego de la visita sus impresiones: $L a$ Argentina y sus grandezas, de Blasco Ibáñez, y Notas de viaje por la América del Sur, de Clemenceau, ex primer ministro francés que volvió a su tierra vivamente impresionado por su descubrimiento de nuestro país".

12. Segundo Luna (2010, p. 181, grifos no original), "Las organizaciones de trabajadores habían aprovechado para pedir que se derogara la Ley de Residencia y que regresaran al país los dirigentes expulsados. Ante el fracaso del pedido, la Confederación Obrera Regional Argentina declaró la huelga general, y el $1^{\circ}$ de Mayo los discursos fueron de encendida protesta. La huelga fue anunciada para el 18, y la respuesta del gobierno no se hizo esperar: el 13 fueron detenidos los redactores de los periódicos obreros, al tiempo que diputados y senadores debatieron la posibilidad de declarar el estado de sitio. Un grupo de ciudadanos asumió la represión: encabezados por el barón Demarchi, Carlos Carlés, el capitán Lara, Juan Balestra y Pedro Luro incendiaron La Protesta, el diario anarquista. También saquearon La Vanguardia, aunque los socialistas no habían adherido a la huelga. La medida de fuerza duró tres días, mientras eran encarcelados unos quinientos dirigentes obreros y el estado de sitio atemorizaba a los manifestantes". Note-se que não era apenas o Estado que atuava na repressão de greves, mas, também, opositores dos movimentos de operários.

13. A memória não valoriza o fato em si, mas a representação, o significado que o mesmo tem para a sociedade em questão e poderá ter para as próximas gerações. Embora o grupo de indivíduos seja mutável, dada a condição da existência humana, as representações acerca dos fatos vividos podem ser compartilhadas, repassadas de geração em geração e, perpetuadas, estando sempre mediadas pelo ambiente cultural e social às quais se encontram vinculadas (Candau, 2012; Halbwachs, 1990). Ainda mais: uma sociedade, mesmo que não tenha vivido determinados fatos que se encontram muito afastados no tempo, pode utilizar-se da História e dos fatos vividos pelos seus antepassados para preencher as lacunas, chegando, inclusive, a "reinventar" um passado e suas representações sobre o mesmo (Halbwachs, 1990).

14. O autor revisitou a trajetória de Moreno nas obras Significación histórica de Mariano Moreno (1938) e El pensamiento vivo de Mariano Moreno (1948).

15. O cerne daquilo que conhecemos como Revolução de Maio dá-se entre os dias 22 a 25 de maio de 1810, embora seja preciso recuar até alguns dias antes para compreender os principais acontecimentos. Entre os dias 18 e 20 de maio, ao receber a notícia de que a Espanha havia caído nas mãos do exército francês, os colonos bonaerenses exigiram ao Vice-rei um Cabildo Abierto com o objetivo de discutir as decisões a serem tomadas a 
partir de então. A sessão do Cabildo transcorreu a partir do dia 22 até a madrugada do dia 23 de maio. No dia 24, foi apresentada uma proposta para a formação da Junta que tinha como presidente o Vice-rei Cisneros. Embora a proposta tenha sido aceita num primeiro momento, na noite do mesmo dia Cornelio Saavedra e Juan José Castelli, então membros dessa primeira formação da Junta, apresentaram suas renúncias exigindo a total deposição do Vice-rei e a formação de um novo corpo governativo sem a presença do mesmo. Neste sentido, no dia 25 de maio apresentou-se uma nova formação para a Junta, que tinha como presidente Cornelio Saavedra. Embora este tenha sido apenas o início do processo independentista no Rio da Prata -que terá, ainda um longo caminho até a efetiva independência das antigas colônias-o período compreendido entre os dias 22 e 25 de maio de 1810 é considerado o momento fundante da nação, por conta da formação do primeiro governo que não reconhecia a autoridade espanhola sobre a região, mesmo que a Junta tenha jurado fidelidade a Fernando VII como recurso de legitimação.

\section{Referências}

Aguerre, M. (2005). Lazos de bronce y mármol. In: Aznar, Yayo; Wechsler, Diana (Comp.). La memoria compartida: Espanha y la Argentina en la construcción de un imaginario cultural: 1898-1950. Buenos Aires: Paidós, p. 47-76.

Beired, J. (2009). O hispano-americanismo historiográfico: Espanha e América na perspectiva de Ricardo Levene e Rafael Altamira. História Unisinos, 13, p. 43-53.

Bernheim, C.T. (1998). La reforma universitaria de Córdoba, Educación superior y sociedad, 9 (1), p. 103-127.

Candau, J. (2012). Memória e identidade. São Paulo: Contexto.

Chartier, R. (2010). Escutar os mortos com os olhos, Estudos Avançados, 24 (69), p. 7-30.

Chiaramonte, J. C. (1993). El problema de los orígenes de los Estados hispanoamericanos en la historiografía recientey el caso del Río de la Plata, Anos 90, 1, p. 49-83.

Devoto, F., \& Pagano, N. (2009). Historia de la historiografía argentina. Buenos Aires: Sudamericana.

Escudero, E. (2010). Ricardo Levene: políticas de la Historia y de la Cultura 1930-1945. Córdoba: Ferreyra Editor.

Fradkín, R.O., \& Gelman, J. (Org.) (2010). Doscientos años pensando la Revolución de Mayo. Buenos Aires: Sudamericana.

Gaut Vel Hartman, S. (2010). Bicentenario 1810-2010. Pensamientos que hicieron la patria. Mariano Moreno, Manuel Belgrano, Cornelio Saavedra, Bartolomé Mitre, Domingo Faustino Sarmiento, Juan Bautista Alberdi. Buenos Aires: Andrómeda.

Halbwachs, M. (1990). A memória coletiva. São Paulo: Edições Vértice.

Levene, R. (1920). Ensayo histórico sobre la Revolución de Mayo y Mariano Moreno. (2 Tomos). Buenos Aires: Facultad de Derecho y Ciencias Sociales.

Lopes, M. B. (2012). O Museo Nacional de la Inmigración: História, memória, representação. Buenos Aires, 1985-2003. São Leopoldo: Oikos; UNISINOS.

Luna, F. (2010). Historia integral de la Argentina. Vol. 10. El largo camino a la democracía. Buenos Aires: Booket. 
Pollak, M. (1992). Memória e identidade social, Estudos Históricos. 5 (10), p. 200-212.

Shumway, N. (2008). A invenção da Argentina. História de uma ideia. São Paulo: Editora da Universidade de São Paulo; Brasília: Editora UnB.

Souto, N., \& Wasserman, F. (2008). Nación. In: Goldman, N. Lenguaje y Revolución. Conceptos políticos clave en el Río de la Plata, 1780-1850. Buenos Aires: Prometeo Libros.

Resumen: Este trabajo tiene por objetivo analizar la obra Ensayo Histórico sobre la Revolución de Mayo y Mariano Moreno (1920), escrita por Ricardo Levene (1885-1959), profesor y miembro de la Junta de Historia y Numismástica; obra inserta en el contexto de las conmemoraciones del Centenario de la Revolución de Mayo de 1810 donde se utilizó la trayectoria de uno de los principales líderes de Mayo para disertar sobre la importancia del Liberalismo para la Revolución. Se pretende analizar las narrativas que Levene construyó sobre la Revolución de Mayo y sobre Mariano Moreno buscando comprender la memoria que construyó acerca del hecho histórico y del personaje así como también sobre la importancia de tales construcciones para el momento que atravesaba la Nación.

Palabras clave: Ricardo Levene - Mariano Moreno - Historiografía argentina - Memoria - Conmemoración.

\begin{abstract}
This work aims to analyze the historical essay on the Revolution of May and Mariano Moreno (1920), written by Ricardo Levene (1885-1959), professor and member of the Board of History and Numismatics, and inserted in the context of the celebrations of the centenary of the May Revolution of 1810, where he used the trajectory of one of the leading May leaders to discuss the importance of liberalism to the Revolution. It is intended here to analyze the narratives that Levene built on the May Revolution and Mariano Moreno, trying to understand the memory that he built on the historical fact and the character as well as the importance of such constructions for the moment lived by the nation.
\end{abstract}

Keywords: Ricardo Levene - Mariano Moreno - Argentine historiography - Memory Celebration.

[Las traducciones de los abstracts fueron supervisadas por el autor de cada artículo] 